\title{
Relationship Between Socioeconomic Status and Body Mass Index Among Adult Nigerians
}

\author{
Mbada C.E. ${ }^{1}$, Adedoyin R.A. ${ }^{2}$, Odejide A.S. ${ }^{1}$ \\ ${ }^{1}$ Physiotherapy Department, Obafemi Awolowo University Teaching Hospitals Complex, Ile -Ife, Nigeria \\ ${ }^{2}$ Department of Medical Rehabilitation, Obafemi Awolowo University, Ile-Ife. Nigeria \\ Correspondence \\ C.E. Mbada, Physiotherapy Department, Obafemi Awolowo University Teaching Hospitals Complex, Ile-Ife, \\ Nigeria • Email: doziembada@yahoo.com
}

\begin{abstract}
SUMMARY
There is a long tradition of observational studies from developed societies linking overweight and obesity to low socioeconomic status (SES). The aim of this study is to assess the relationship between SES and obesity and determine whether variations in the body mass index (BMI) of adult Nigerians is influenced by their SES.

The height and body weight of 1067 adults, aged 30 - 60 years were measured and their BMI was calculated. A structured questionnaire which assessed socioeconomic (SE) variables such as income, education and occupation was used to objectively classify the participants into the different SE strata. A pictorial self-rating SES ladder of nine rungs was employed to assess the participants' SES and to test the validity of the questionnaire. A high correlation ${ }^{\circledR}=0.951, \mathrm{P}<0.01$ ) was found between the two SES assessment tools. SE scores were found to be inversely related to weight $\mathbb{R}=-0.113, \mathrm{P}<0.01$ ) and $\mathrm{BMI}\left({ }^{\circ}=-0.172, \mathrm{P}<0.01\right)$, respectively. There was a significant relationship $\left(\mathrm{X}^{2}=32.853 ; \mathrm{p}=0.000\right)$ between BMI categories and SES. Individuals in the lower SES had higher rates of overweight $(24.8 \%)$ and obesity $(12.9 \%)$. There were significant differences in the weight $(F=8.407 ; p=0.000)$ and BMI $(F=20.66 ; p=0.000)$ across the different SE strata.

An inverse relationship was found between SES and BMI. Individuals in the lower SE strata had a greater BMI and a higher prevalence of overweight and obesity.
\end{abstract}

KEY WORDS: socioeconomic status, body mass index, overweight, obesity

\section{INTRODUCTION}

Overweight is defined as a body weight that exceeds the acceptable weight for a particular person, based on the individual's age, height and/or frame size (Kuczmarski, 2000). It is also defined as a body mass index (BMI) of 25$29.9 \mathrm{~kg} / \mathrm{m}^{2}$; whereas, obesity is defined as a BMI greater than or equal to $30 \mathrm{~kg} / \mathrm{m}^{2}$ (WHO, 1998; Uwaifo and Arioglu, 2004). Several classifications and definitions exist for degrees of obesity, the most widely accepted being the World Health Organization (WHO) criteria, based on BMI (Uwaifo and Arioglu, 2004). Body mass index is a measure of ponderosity or heaviness and it is calculated by dividing weight in kilogrammes by height in metres squared - Wkg/Hm ${ }^{2}$ (Himes, 1999). According to Uwaifo and Arioglu (2004), BMI is far more commonly used to define obesity and has been found to closely correlate with the degree of body fat in most settings.

Obesity constitutes a significant public health problem in the developed world (WHO, 1997; Siedel, 1997;
Sorenson, 2000; Uwaifo and Arioglu, 2004). The prevalence is also increasing rapidly in several developing nations worldwide, and it is associated with high morbidity and mortality (Uwaifo and Arioglu, 2004). Obesity which is often perceived as a cosmetic problem in adults, is associated with high blood pressure, type 2 diabetes and abnormal levels of total cholesterol (Gail et al, 2005; Colhoun et al, 1998). The recent upsurge in its prevalence in developing countries is believed to be linked to the acculturation resulting from Westernization that these nations are undergoing, with alterations in diet and activity patterns (WHO, 1997; Popkin, 1994). The aetiology of obesity is multi-factorial; genetic predisposition and environmental factors having been implicated in most studies (Maes et al, 1997; Hill et al, 2000). In the past, however, socioeconomic status (SES) has been an importantfactor associated with high incidences of obesity (Sobal and Stunkard, 1989; Flegal et al, 2002; Hardy et al, 2000; Lyratzopoulos et al, 2005). Several studies using individual measures of socioeconomic (SE) variables such 
as income, education and occupation, have shown that individuals in the lower SE strata are more likely to be obese as shown by an increase in BMI with decreasing SE scores. (Lahmann et al, 2000; Hardy et al, 2000; Lyratzopoulos et al, 2005). Studies conducted in the US also show that people in the lower SE stratum and minority groups have a higher prevalence of obesity (Sobal and Stunkard, 1989). According to Uwaifo and Arioglu (2004), data from Africa on this issue is scant, though a clear and distinct secular trend of profoundly increasing BMI clearly exists when people from Africa migrate to the countries in the Northwestern hemisphere.

\section{MATERIALS AND METHODS}

\section{Participants}

A total of 1067 adults: 552 males $(51.7 \%)$ and 515 females $(48.3 \%)$, whose ages ranged between 30 - 60 years were consecutively recruited for this study. The setting for this study was the ancient city of Ile-Ife, Nigeria. Ile-Ife is a semi-urban community in southwestern Nigeria.

\section{Procedures}

The participants were fully informed about the purpose of the study and their consent was obtained before measurements were taken. Subjects' height and weight were measured and their ages recorded. The BMI (Uwaifo and Arioglu, 2004) was later calculated as:

$$
\text { BMI = weight }[\mathrm{kg}]) / \text { height }[\mathrm{m}] 2
$$

A modified version of the SES questionnaire used by Balogun et al (1990) was used to collect information on the subjects' highest educational attainment, level of income and occupational status. This was used to classify the subjects into the 3 different SE strata. The scoring of the questionnaire items was based on their status in the society. Based on the summative score, the participants were categorized into lower $(<9)$; middle $(10-18)$ or higher(19 -27) SE stratum.

Due to the cultural inhibitions and reluctance of Nigerians about disclosing their properties and status (Adedoyin et al, 2006), a pictorial self-rating SES ladder of nine rungs adopted from the MacArthur research network on SES (John and MacArthur, 2000) was also employed to subjectively assess the participants' SES and to test the validity of the questionnaire. Each rung of the ladder was assigned a score of 3 and a maximum score of 27 is possible for any participant that rates him/herself to be on the 9 th rung.

\section{Analysis}

Overweight and obesity were defined using the WHO BMI classification as follows: underweight $=<18.5 \mathrm{~kg} / \mathrm{m}^{2}$, normal $=>18.5-24.9$, overweight $=>25-29.9 \mathrm{~kg} / \mathrm{m}^{2}$ and obese $=>30 \mathrm{~kg} / \mathrm{m}^{2}(\mathrm{WHO}, 1998)$.

Descriptive statistics of mean and standard deviation were used to summarize the data collected. Pearson's moment correlation analysis was used to determine the relationship between the SE scores and each of weight, height and BMI of the participants. Chi square test was used to determine the association between the BMI categories and SES. One-way analysis of variance (ANOVA) was used to determine if there was any significant difference between the age, weight, height and BMI of the participants in the three SE strata. Least significance difference (LSD) post-hoc analysis was used to probe the specific differences found in the F-ratio of the ANOVA. The significance level was set at $\mathrm{P}<0.05$.

\section{RESULTS}

The mean age of the participants was $44.33 \pm 6.78$ years, mean height $1.66 \pm 8.58 \mathrm{~m}$, mean weight and BMI were $64.41 \pm 11.46 \mathrm{~kg}$ and $23.45 \pm 3.89$, respectively. The age of the participants ranged from 30-60 years. The physical characteristics of the participants by gender are presented in table 1 . A little over half $(51.7 \%)$ of the participants were male, while $48.3 \%$ were female. The male participants were generally heavier and taller. A high positive concurrent-criterion validity was obtained ${ }^{\circledR}=-0.951, \mathrm{P}<$ 0.01 ) between the modified questionnaire and the SE ladder that were used to classify the participants into the different SE strata.

Table 1. Summary of the mean values of the physical characteristics of the male and the female participants

\begin{tabular}{lcc}
\hline $\begin{array}{l}\text { Dependent } \\
\text { variables }\end{array}$ & $\begin{array}{c}\text { Male subjects } \\
(\mathrm{n}=552)\end{array}$ & $\begin{array}{c}\text { Female subjects } \\
(\mathrm{n}=515)\end{array}$ \\
\hline Age & $44.96 \pm 6.94$ & $43.65 \pm 6.55$ \\
Height & $1.6689 \pm 8.376$ & $1.649 \pm 8.679$ \\
Weight & $65.56 \pm 11.18$ & $63.18 \pm 11.63$ \\
BMI & $23.55 \pm 3.776$ & $23.344 \pm 4.003$ \\
\hline
\end{tabular}

A correlation matrix between SE scores and each of age, height, weight and BMI of all the participants is presented in table 2. A significant but low inverse correlation was found between SE scores and each of weight $\left.{ }^{\circledR}=-0.113, \mathrm{p}<0.01\right)$ and $\mathrm{BMI}{ }^{\circledR}=-0.172 ; \mathrm{p}<$ $0.01)$. 
Relationship between Socioeconomic Status and Body Mass Index among Adult Nigerians

Table 2. Correlation matrix between socioeconomic score and the dependent variables of all the participants

\begin{tabular}{|c|c|c|c|c|c|}
\hline & \multicolumn{5}{|c|}{$\begin{array}{c}\text { Correlation coefficient }(\mathrm{r}) \\
\text { ( } \mathrm{p} \text {-value })\end{array}$} \\
\hline & SE scores & Age & Height & Weight & BMI \\
\hline \multirow[t]{2}{*}{ SE scores } & & 0.037 & 0.035 & -0.113 & -0.172 \\
\hline & & 0.633 & 0.097 & 0.013 & 0.000 \\
\hline \multirow[t]{2}{*}{ Age } & 0.037 & & -0.014 & -0.005 & 0.001 \\
\hline & 0.633 & & 0.654 & 0.875 & 0.979 \\
\hline \multirow[t]{2}{*}{ Height } & 0.035 & -0.014 & & 0.364 & -0.202 \\
\hline & 0.097 & 0.654 & & 0.000 & 0.000 \\
\hline \multirow[t]{2}{*}{ W eight } & -0.113 & -0.005 & 0.364 & & 0.834 \\
\hline & 0.013 & 0.875 & 0.000 & & 0.000 \\
\hline \multirow[t]{2}{*}{ BMI } & -0.172 & 0.001 & -0.202 & 0.834 & \\
\hline & 0.000 & 0.979 & 0.000 & 0.000 & \\
\hline
\end{tabular}

$\mathrm{P}<0.05, \mathrm{P}<0.001$

On gender stratification, weight $\left.{ }^{\circledR}=-0.131 ; \mathrm{p}<0.003\right)$ and $\left.\mathrm{BMI}{ }^{\circledR}=-0.123 ; \mathrm{p}<0.005\right)$ showed a significant inverse correlation with SE scores among the male participants, while only BMI ${ }^{\circledR}=-0.093$, p $<0.028$ ) was significantly correlated with SE scores among the female participants. Chi square test revealed a significant association between the different BMI categories, SES of the participants and gender stratification, as shown in table 3. The prevalence of overweight and obesity was higher among individuals in the lower SE stratum (table 3).

Of the study population, 319 (29.9\%) (163 males and 156 females) belong to the lower SE stratum, 460 (43.1\%) (229 males and 231 females) belong to the middle SE stratum and 288 (27\%) (160 males and 128 females) belong to the higher SE stratum. The one-way ANOVA summary and its post-hoc comparison of the physical characteristics of the participants by SE stratum is presented in table 4 . The participants in the lower and higher SE strata were significantly older than those in the middle SE stratum. The participants in the lower SE stratum have significantly higher weight and BMI. There was, however, no significant difference in the weight and BMI of the participants in the middle and higher SE strata.

Table 3. Chi square test of association between BMI categories, SES of participants and gender

\begin{tabular}{|c|c|c|c|c|c|}
\hline & \multicolumn{3}{|c|}{ Socioeconomic Stratum } & \multirow{2}{*}{$X^{2}$} & \multirow{2}{*}{$\mathrm{p}$-value } \\
\hline & Lower & Middle & Higher & & \\
\hline \multicolumn{6}{|l|}{ All participants } \\
\hline Underweight & $22(6.90 \%)$ & $33(7.17 \%)$ & $22(7.63 \%)$ & 32.853 & 0 \\
\hline Normal weight & $177(55.5 \%)$ & $314(68.3 \%)$ & $210(72.9 \%)$ & & \\
\hline Overweight & $79(24.8 \%)$ & $87(18.9 \%)$ & $42(14.6 \%)$ & & \\
\hline Obese & $41(12.9 \%)$ & $26(5.65 \%)$ & $14(4.86 \%)$ & & \\
\hline Total & 319 & 460 & 288 & & \\
\hline \multicolumn{6}{|l|}{ All male } \\
\hline Underweight & $13(8.33 \%)$ & $26(11.3 \%)$ & & 21.992 & 0.001 \\
\hline Normal weight & $82(52.6 \%)$ & $155(67.4 \%)$ & & & \\
\hline Overweight & $45(28.9 \%)$ & $36(15.7 \%)$ & & & \\
\hline Obese & $16(10.3 \%)$ & $13(5.65 \%)$ & & & \\
\hline Total & 156 & 230 & 128 & & \\
\hline \multicolumn{6}{|l|}{ All female } \\
\hline Underweight & $9(5.52 \%)$ & $7(3.04 \%)$ & $10(6.25 \%)$ & 22.894 & 0.001 \\
\hline Normal weight & $95(58.3 \%)$ & $159(69.1 \%)$ & $117(73.1 \%)$ & & \\
\hline Overweight & $34(20.9 \%)$ & $51(22.2 \%)$ & $27(16.9 \%)$ & & \\
\hline Obese & $25(15.3 \%)$ & $13(5.65 \%)$ & $6(3.75 \%)$ & & \\
\hline Total & 163 & 230 & 160 & & \\
\hline
\end{tabular}

Significant level was set at $\mathrm{P}<0.05$

$\mathrm{BMI}=$ Body mass index

SES $=$ Socioeconomic status 
Table 4. Summary of the one way analysis of variance and least square difference post-hoc test between the three socioeconomic strata

\begin{tabular}{lccccc}
\hline & \multicolumn{3}{c}{ Socioeconomic groups } \\
\cline { 2 - 5 } Variables & $\begin{array}{c}\text { Lower } \\
\mathrm{n}=319\end{array}$ & $\begin{array}{c}\text { Middle } \\
\mathrm{n}=460\end{array}$ & $\begin{array}{c}\text { Higher } \\
\mathrm{n}=288\end{array}$ & F-ratio & P-value \\
\cline { 2 - 5 } Age & $45.74 \pm 7.17^{\mathrm{a}}$ & $42.22 \pm 6.48^{\mathrm{b}}$ & $46.13 \pm 8.6^{\mathrm{a}}$ & 2.962 & 0 \\
Height & $1.65 \pm 9.03^{\mathrm{a}}$ & $1.67 \pm 7.61^{\mathrm{b}}$ & $1.66 \pm 9.30^{\mathrm{a}}$ & 7.471 & 0.001 \\
Weight & $66.40 \pm 13.4^{\mathrm{a}}$ & $64.24 \pm 10.7^{\mathrm{b}}$ & $62.49 \pm 10.01^{\mathrm{b}}$ & 8.407 & 0 \\
BMI & $24.59 \pm 4.42$ & $23.15 \pm 32.79^{\mathrm{b}}$ & $22.68 \pm 3.05^{\mathrm{b}}$ & 20.664 & 0 \\
\hline
\end{tabular}

Note: a, b. For a particular variable, mode means with different superscripts are significantly different $(\mathrm{P}<0.05)$. Mode means with same superscripts are not significantly different $(\mathrm{P}<0.05)$.

\section{DISCUSSION}

This study investigated the relationship between SES and BMI in a semi-urban setting in Nigeria. The relationship between SES and obesity in developing countries has been inconsistent and controversial. Previous investigators have reported the relationship between SES and obesity in developing countries to be positive and strong; implying that the higher the SES the more the obesity (Stunkard, 1997; Rissanen, 1997; Bovet et al, 2003; Bunker et al, 1992; Gilbert et al, 1994). On the other hand, a consistent and strong inverse relationship has been established between SES and obesity in the developed Western societies (Stunkard,1997; Rissanen, 1997; Sobal and Stunkard, 1989; Winkleby et al, 1992). However, Fezeu et al (2006) submitted that the reported positive relationship between SES and obesity may not be true for all developing societies. It is believed to be highly dependent upon the stage of industrial development of a country or region (Sobal and Stunkard, 1989; Sorensen, 1995).

The present study revealed a low inverse correlation between SE scores and each of weight and BMI. This finding is at variance with previous studies in developing societies which report a positive relationship between SES and obesity. Our findings, however, lean towards the studies from developed countries that reported SE variables such as income, education and occupation to be inversely related to body fat (Shah, 1989; Dressler, 1990; Stunkard, 1997; Rissanen, 1997; Sobal and Stunkard, 1989; Winkleby et al, 1992).

The results in this study also showed that individuals in the lower SE stratum have higher BMI values. This finding supports observational studies linking overweight and obesity to poor SES (Averett and Korenman, 1999; Cawley, 2004). Our findings are consistent with studies from the developed Western countries which reported that adults in the low SE stratum have higher BMI than their better educated and wealthier counterparts (Flegal et al, 2000; Kuczmarski et al, 2000; Reilly et al, 2003). However, this finding is at variance with another study from Ghana, a developing country in West Africa, where higher/middle class subjects exhibited higher BMI values compared to subjects from the lower class (Amoah, 2003). Despite the reported positive relationship between SES and obesity in developing countries, recent studies have shown that the increasing economic and social development of each country, particularly in the developing countries, seems to rapidly shift the burden of obesity towards the poor, thus, increasing the rate of obesity among poor people (Popkin, 2002; Monteiro et al, 2004; Song 2006).

The results in this study showed that in all the different SE strata, female participants had higher rates of overweight and obesity, with the exception of the middle SES, where the prevalence of obesity was similar among both genders. In this study, the percentage of participants with obesity in the lower SES was more than twice that of those in the middle and higher SE strata. On gender differentiation, the percentage of males in the lower SE stratum was almost twice that of middle and higher SE strata, while the percentage among females in the lower SE stratum was more than thrice that of middle and higher SE strata.

Our findings suggest that low level of education and poverty among individuals in the lower SES, may have been responsible for the inverse relationship between SES and each of overweight and obesity; the higher BMI values and higher rates of overweight and obesity. These may have resulted from poor food habits, where quantity is valued above quality (Adedoyin et al, 2005), low level of awareness of health hazards of obesity and cultural values favouring plump body shapes as a symbol of privilege and wealth (Brooks, 2006; Song, 2006) or as a sign of good living (Adedoyin et al, 2005). 
There is the need to educate the general public about the risks associated with being overweight/obese, the need to imbibe healthy eating habits and change cultural preferences for plump bodies as against bodies with lower BMI. Finally, economic empowerment to combat poverty is essential in Africa and the entire third world countries in other to improve the health of her people.

\section{ACKNOWLEDGEMENTS}

We are grateful to Dr. B.O.A. Adegoke for the critical preview of this manuscript before submission.

\section{References}

Adedoyin, R.A., Mbada, C.E., Awofolu, O.O. and Oyebami, O.M. (2005) The influence of socioeconomic status on casual blood pressures of the adult Nigerians. European Journal of Cardiovascular Prevention and Rehabilitation 12, pp. $271-273$.

Amoah, A.G.B. (2003) Obesity in adult residents of Accra, Ghana. Ethnicity and Disease 13(2), pp. 97-101.

Averett, S. and Korenman S. (1999) Black-white differences in social and economic consequences of obesity. International Journal of Obesity 23(2), pp.166-173.

Balogun, J.A., Obajuluwa, V.A., Olaogun, M.O.B., Oyeyemi, A.Y., Balogun, M.O. and Adeodu, O.O. (1990) Influence of parental socioeconomic status on casual blood pressures of Nigerian school children. International Journal of Cardiology 29, pp.63-69.

Bovet, P., Ross, A.G., Gervasoni, J.P., Mkamba, M., Mtasiwa, D.M., Lengeler, C., Whiting, D. and Paccaud, F. (2002) Distribution of blood pressure, body mass index and smoking habits in the urban population of Dar-es- Salaam, Tanzania and associations with socioeconomic status. International Journal of Epidemiology 31, pp.240-47.

Brooks, B. (2006) Obesity as a Culture-bound Syndrome: the impacts of socioeconomics and body image.

Bunker, C.H., Ukoli, F.A., Nwankwo, M.U., Omene, J.A., Currier, G.W., Holifield-Kennedy, L., Freeman, D.T., Vergis., E.N, Yeh, L.L. and Kuller, L.H. (1992) Factors associated with hypertension in Nigerian civil servants. Preventive Medicine 21: pp.710-22.

Cawley, J. (2004) The impact of obesity on wages. The Journal of Human Resources. 39(2), pp.451-474.

Colhoun, H., Hemingway, H. and Poulter, N.R. (1998) Socioeconomic status and blood pressure: an overview analysis. Journal of Human Hypertension 12, pp.91-110.

Dressler, W.W. (1990) Education, lifestyle and arterial blood pressure. Journal of Psychosomatic Research 34, pp.515- 523.

Flegal., K.M., Carroll, M.D., Ogden, C.L., and Johnson C.L. (2002) Prevalence and trends in obesity among US adults,
1999-2000. Journal of American Medical Association 288(14), pp.1723-7.

Flegal., K.M. and Troiano, R.P. (2000) Changes in the distribution of body mass index of adults and children in the US population. International Journal of Obesity and Related Metabolic Disorders 24, pp.807-818.

Gail, D.H., Gloria. A.A. and Bern'Nadette, K. (2005) Obesity and the African-American adolescent in Mississippi: an overview. Southern Medical Journal 98(1), pp.72-78.

Gilberts, E.C., Arnold, M.J., Grobbee, D.E. (1994) Hypertension and determinants of blood pressure with special reference to socioeconomic status in a rural south Indian community. $J$. Epidemiol. Community Health 48, pp.258 - 61.

Hardy, R., Wadsowrth, M., Kuh, D.(2000) The influence of childhood weight and socioeconomic status change in adult body mass index in a British national birth cohort. International Journal of Obesity and Related Metabolic Disorders 24(6), pp.725-34.

Hill, J.O., Wyatt, H.R., Melanson, E.L. (2000) Genetic and environmental contributions to obesity. Medical Clinic of North America 84(2) 333-46.

Himes, J.H. (1999) Agreement among anthropometric indicators identifying the fattest adolescents. International Journal of Obesity 23(2), pp.18-21.

John, D. and MacArthur, C.T. (2000) The MacArthur Scale of Subjective Social Status. Research Network on Socioeconomic Status and Health.

Kuczmarski, R.J., Flegal., K.M. (2000) Criteria for definition of overweight in transition: background and recommendations for the United States. American Journal of Clinical Nutrition 72, pp.1074-81.

Lyratzopoulos, G., McElduff, P., Heller, R.F., Hanily, M. and Lewis, P.S. (2005) Mid-term body mass index increase among obese and non-obese individuals in middle-life and deprivation status. BMC Public Health 5, pp.32.

Maes, H.H.M., Neale, M.C. and Eaves, L.J. (1997) Genetic and environmental factors in relative body weight and human adiposity. Behavior Genetics 27, pp.325-351.

Monteiro, C.A., Moura, E.C., Conde, W.L. and Popkin, B.M. (2004) Socioeconomic status and obesity in adult populations of developing countries: a review. Bulletin of World Health Organization 82, pp.940-46.

Popkin, B.M. (1994)The nutrition transition in low income countries: an emerging crisis. Nutr Rev 52, pp.285-298.

Reilly, J.J., Methven, E. and McDowell, Z.C. (2003) Health consequences of obesity. Archive of Diseases in Childhood 88, pp.748-752.

Shah, M., Jeffery, R.W., Hannan, P.J. and Onstad, L. (1989) Relationship between socio-demographic and behaviour variables, body mass index in a population with high-normal blood pressure: hypertension prevention trial. Euro J Clin Nutr 43, pp.583-96. 
Siedel, J.C. (1997) Time trend in obesity: an epidemiological perspective. Horm Metab Res 29, pp.155-158.

Sobal, J. and Stunkard, A.J. (1989) Socioeconomic status and obesity: a review of the literature. Personality and Social Psychology Bulletin 105, pp.260-75.

Song, YM. (2006) Commentary: Varying relation of socioeconomic status with obesity between countries at different stages of development. International Journal of Epidemiology 35(1), pp.112-113.

Sorenson, T.I.A. (2000) The changing lifestyle in the world; body weight and what else. Diabetic Care 23(2), pp.1-4.

Strauss, R.S. (2000) Childhood obesity and self-esteem. Pediatrics 105, p. 15 .
Uwaifo, G. and Arioglu, E. (2006). Obesity: www.emedicine.com/med/topic1653.htm.11/12/2007.06:38pm

World Health Organization (2000) Defining the problem of overweight and obesity. In: World Health Organization. Obesity: preventing and managing the global epidemic: report of a WHO Consultation. Geneva. pp.241-3. (WHO Technical Report Series, 894).

World Health Organization (WHO) (1998) Obesity: preventing and managing the global epidemic. Report of a WHO Consultation. Presented at the World Health Organization, June 3-5, 1997; Geneva, Switzerland. Publication WHO/NUT/NCD/98. 1:1998 